\title{
Do Smooth Waters Run Deep? Alcohol Intoxication and the Effects of Water Consumption on Driving-Related Cognitions and Behavior
}

\author{
N.L. Spaanjaars R. Spijkerman R.C.M.E. Engels \\ Behavioural Science Institute, Radboud University Nijmegen, Nijmegen, The Netherlands
}

\section{Key Words}

Water $\cdot$ Alcohol $\cdot$ Cognitions $\cdot$ Risky driving behavior . Driving simulator

\begin{abstract}
The present study tested the effect of the combined use of alcohol and water on driving-related cognitions and behavior. Seventy-four female students performed a driving simulator task after having consumed alcohol or a placebo. Additionally, half of the participants consumed 0.5 liter of water. It was hypothesized that combining alcohol and water could lead to an underestimated perceived intoxication level resulting in more favorable driving cognitions and increased risk behavior. Our findings showed that the combined use of water and alcohol did not affect cognitions or behavior. Surprisingly, in the placebo condition, water intake increased risky driving cognitions and behavior in women with a history of accident involvement. Lacking a clear counterproductive effect when combined with alcohol, water could be a useful tool in limiting alcohol use among female drinkers.
\end{abstract}

Copyright $\odot 2010$ S. Karger AG, Basel

\section{Introduction}

'Water is good for our health, our looks and even for our brain.' At least, that is the message that water-selling companies convey in their advertisements propagating
'The cleansing water' or 'Your natural source of youth'. Water consumption has also been promoted as a harm reduction measure in drug prevention projects in party settings. For example, drug users at dance events are advised to drink water to prevent dehydration [1]. In the Netherlands, a recent outreach prevention project involved the provision of bottles of water to partying people in bars in order to decrease alcohol use. The rationale for this project is that water consumption increases satiety and will therefore decrease alcohol consumption.

However, there is no apparent evidence for the benefits attributed to increased water consumption $[2,3]$. Moreover, the effects of combining water with a substance like alcohol are unclear and may even be detrimental if people assume that increased water intake can promote clearance of toxins from the body [4-6]. When combining alcohol, i.e. a toxin, with water, this belief about clearance of toxins might lead to the perception that one's intoxication level is lower than it actually is. Importantly, perceptions of one's intoxication level determine judgments about one's overall level of functioning after alcohol use [7]. The dominant finding of research on drinkers' selfevaluations of intoxication is that people tend to be poor estimators of their level of intoxication $[8,9]$ and this, in turn, could affect subsequent driving behavior [10]. Thus, depending on drinkers' personal perceptions of their intoxication level, they might engage in risky behavior such as driving under influence.

\section{KARGER}

Fax +41613061234 E-Mail karger@karger.ch www.karger.com
(C) 2010 S. Karger AG, Basel

$1022-6877 / 11 / 0171-0021 \$ 38.00 / 0$

Accessible online at:

www.karger.com/ear
Renske Spijkerman

Behavioural Science Institute, Radboud University Nijmegen

Montessorilaan 3

NL-6525 HR Nijmegen (The Netherlands)

Tel. +31 24361 5767, E-Mail r.spijkerman @ pwo.ru.nl 
We propose that water beliefs might moderate this process by amplifying the underestimation of intoxication, leading to increased risk behavior. Although this topic has received little attention in previous research, a recent study by Fillmore et al. [8] corroborates this hypothesis. Testing the impact of expectations about caffeine on alcohol-induced impairment, Fillmore et al. [8] showed that groups expecting caffeine antagonism anticipated less impairment from an alcohol-caffeine combination but, ironically, showed greater impairment on a psychomotor task than those expecting no counteraction. This suggests that expectations about counteracting effects of caffeine lead to decreased compensation for the impairing impact of alcohol use on performance. Thus, subjects display higher levels of impairment after using alcohol and another substance if this other substance is expected to attenuate alcohol-related behavioral impairment. This might also hold for the combined use of alcohol and water. Because of the cleansing image of water, people might assume that drinking water will counteract the effects of alcohol, leading to biased self-perceived intoxication levels that subsequently affect behavior.

One area in which alcohol induced-impairment poses a real danger is traffic. According to previous research, alcohol is the most important human factor contributing to the occurrence of severe automobile crashes [11]. Ample studies have demonstrated the impact of alcohol use on driving tasks such as lane keeping, brake latency and hazard perception $[12,13]$ and on the willingness to engage in high-risk situations [14]. Especially young drivers are at risk since they are both inexperienced drivers and relatively inexperienced drinkers. The latter increases their risk of having an accident involving alcohol consumption [15-17]. Prior accident involvement, in turn, is related to subsequent accident involvement [18] and indicative of being a high-risk driver [19]. Possibly, highrisk drivers are more prone to the effects of water since believing in the antagonistic effect of water justifies engagement in potentially dangerous behaviors. Hence, accident involvement was taken into account when examining the effect of water.

The present study was aimed at testing the effects of the combined use of alcohol and water. For this purpose, we used an alcohol administration paradigm in an experimental design with a simulated driving task. Our aim was twofold; examining the impact of drinking water in combination with alcohol on driving-related cognitions, and its impact on driving performance during a simulated driving task. Since women generally consume more water than men [20] and our pilot data showed stronger beliefs about the cleansing effect of water in women, we assumed that they might be more susceptible to its effects. This study was therefore conducted on female participants. It was expected that women who combined water and alcohol would underestimate their intoxication level and would show more favorable driving cognitions and increased risk-behavior during a driving task, compared with women who only drank alcohol. Prior accident involvement was expected to moderate these relationships in such a way that the risk-increasing effect of water would be especially present in women who had been previously involved in an accident.

\section{Method}

We first examined whether people really endorsed the belief that water cleanses the body from toxins in a sample of 42 college students (12 men, 30 women). In general, people agreed with this proposition $($ mean $=4.90, \mathrm{SD}=1.12$, range $=1-6)$. Moreover, an ANOVA showed that women tended to have stronger beliefs in the purifying properties of water $($ mean $=5.10, \mathrm{SD}=0.20)$ than men (mean $=4.42, \mathrm{SD}=0.32)[\mathrm{F}(1,40)=3.36, \mathrm{p}=0.07]$. More information about this pilot study can be requested from the authors.

\section{Participants}

Eighty-three female college students were recruited by posters on the campus and a message posted on an online participant platform. Since knowledge of the actual purpose of the study could influence the results, participants were led to believe that the study was about the effects of alcohol on driving performance. The actual purpose was, of course, to examine the effects of water combined with alcohol on driving cognitions and behavior.

Since the legal age for drinking hard liquor and for driving is 18 in the Netherlands, participants had to be 18 or older. Other inclusion criteria were: a driver's license for $1-5$ years and consumption of at least 2 alcoholic drinks per week. Four participants experienced sickness during the test drive and were consequently unable to proceed. Five participants were excluded from the analyses because they reported not to believe they consumed alcohol. The final sample consisted of 74 females aged 19-25 years (mean $=21.85, \mathrm{SD}=1.54)$. They drank an average of 8.5 standard alcoholic drinks per week $(S D=5.78)$. Participants had had their driver's license on average for 34.3 months $(S D=15.41)$ and drove on average 1-3 times a month.

\section{Procedure}

The experiment had a 2 (alcohol or placebo) $\times 2$ (water or no water) between-subject controlled placebo design. Participants were randomly assigned, each receiving a cocktail with a different content depending on which group they were in. Subjects in the alcohol conditions received a cocktail containing tonic and vodka ( $40 \%$ alcohol by volume, mixture of $4: 1$ ) that produced a blood alcohol content (BAC) of $0.03 \mathrm{mg} / \mathrm{l}\left(\mathrm{BAC}\right.$ at $\mathrm{T}_{2}$ : mean $=0.03 \mathrm{mg} / \mathrm{l}$, $\mathrm{SD}=0.01 ; \mathrm{BAC}$ at $\mathrm{T}_{3}$ : mean $\left.=0.02 \mathrm{mg} / \mathrm{l}, \mathrm{SD}=0.01\right)$. As a reference, the statutory limit for novice drivers in the Netherlands is $0.02 \mathrm{mg} / \mathrm{l}$. Exact alcohol doses were determined by using the for- 
mula described by Deitrich and Palmer [21], taking weight and sex into account. Participants in the placebo conditions drank a cocktail containing an equivalent amount of tonic, poured out of a vodka bottle. Moreover, olfactory cues were produced by putting vodka and a lemon piece soaked in vodka on the rim of the glass. The cocktail also contained two drops of Tabasco to create a warm sensation similar to the sensation of alcohol when it is consumed. The procedure of this study was judged and approved by the ethical committee.

Upon arrival in the laboratory, participants filled out a medical checklist and signed the informed consent form. Participants were excluded if they reported physical or psychological problems, current use of drugs or medications, pregnancy, or breastfeeding. Since participants were instructed to start the experiment sober, sobriety was checked using a breathalyzer. To test simulator sickness, we invited participants to perform a 3-min test drive through a city area which contained no complicated traffic situations. Simulator sickness is caused by the incongruence between the visual system experiencing motion and the driver remaining stationary. Symptoms are nausea, disorientation and ocular problems [22]. Four participants experienced sickness during the test drive and were consequently unable to proceed. All others were invited to go to another room, where they filled out the first part of the questionnaire.

After completion, participants were requested to drink a large cocktail $(400 \mathrm{ml})$ which either contained alcohol and tonic or just tonic in $10 \mathrm{~min}$. The consumption of this cocktail was followed by a manipulation check, i.e. a single question asking participants how many standard alcohol drinks they thought their cocktail contained. Answers could be given on an 8-point scale (range = $0-7$ ). Then participants had to wait for $20 \mathrm{~min}$ in order to let the alcohol be taken up by their body. Participants in the water conditions received a bottle containing 0.5 liter of still mineral water (Spa) and were asked to drink it while waiting. After $20 \mathrm{~min}$, the researcher returned and asked the participant to fill out the second part of the questionnaire. After completion, BAC was measured and participants were taken to the driving simulator. They were instructed to drive as they would normally do and were left alone to perform the task. When participants finished, they filled out the third part of the questionnaire. Finally, participants were thanked and received EUR 15 or 1.5 course credit.

\section{Apparatus and Materials}

Driver's experience was measured by four questions, i.e. driving frequency in the past year, duration (in months) of driver's license, and whether and how often they had been involved in a car accident inflicting damage or had driven a car while being intoxicated.

Alcohol use was measured by the Quantity Frequency Variability (QFV) method, which consists of five questions asking how many week and weekend days participants had consumed alcohol in the past 4 weeks $(\mathrm{F})$ and how many glasses participants on average had drunk on these week and weekend days (Q). The fifth question asked participants whether they had ever drunk 4 or more glasses in 1 day during the past 6 months (V) [23]. Scores for quantity and frequency were computed by multiplying the number of days with the number of drinks consumed on weekend days (Friday to Sunday) and adding this to the multiplication of days and number of drinks on weekdays (Monday to Thursday). Variability scores were used as a measure of binge drinking.

Effects of Water on Driving Cognitions and Behavior
Perceived level of intoxication was measured using two visual analogue scales: (1) 'To what extent do you feel intoxicated at this very moment?'; (2) 'To what extent do you think that your overall functioning at this very moment is influenced by the alcohol you drank?'. The scales consisted of a 100 -mm horizontal line, the left end indicating 'not at all' and the right end indicating 'very much'. Participants indicated their perceived level of intoxication by placing a mark on the line at the point that fitted their feeling [8]. Scores ranged from 0 to 100 . Since both items were highly correlated $(\mathrm{r}=0.84, \mathrm{p}<0.01)$, we computed the average score of both questions to determine overall perceived intoxication level.

Driving-related cognitions were also measured using two visual analogue scales assessing ability and willingness to drive: (1) 'To what extent do you think you are able to drive a car safely at this very moment?'; (2) 'Suppose you had to drive a real car at this very moment; how willing to drive would you be?' [8].

Vehicle handling and driving performance were measured when participants performed a 25 -min task in a fixed-base driving simulator consisting of a cockpit including steering wheel, indicators, seatbelt and pedals. The cockpit was surrounded by three 50 -in plasma screens which covered a $210^{\circ}$ view horizontally and $41^{\circ}$ vertically. The simulation software simulated autonomic and interactive traffic, creating a natural traffic environment. The simulator and its software were used in other studies and proved to be valid for assessing driving behavior $[24,25]$. During the ride, participants encountered situations in urban, rural and highway areas in which their response was measured. Gap acceptance, the time headway between two vehicles into which a driver chooses to turn, was assessed while participants turned left on a road with upcoming traffic $[24,26]$. In addition, participants' response to a traffic light turning orange was assessed [27]. To measure participants' reaction on a sudden incident, fog appeared while driving on the motorway. During this incident, minimum speed was measured. To assess vehicle handling, speed and lateral position were measured constantly during the driving task. Previous research has shown that measures like these are sensitive to the effects of drug use in general [24] and alcohol in particular [28].

BACs were determined from breath samples using a Lion SD400 breath analyzer.

Confounding variables such as thirst and craving for alcohol were measured using visual analogue scales. To measure a subject's belief about water, participants reported how strongly they agreed with the propositions 'Drinking water cleanses the body', 'Drinking water reduces the effect of alcohol, so drinking water will make you less drunk' and 'Drinking water at the end of a night out makes you sober up faster' on a 6-point scale ( 1 = 'Strongly disagree' to 6 = 'Strongly agree'). Lastly, participants also completed the Domain Specific Risk Taking (Adult) Scale [29].

\section{Results}

Data were analyzed by conducting analyses of variance (ANOVA), covariance (ANCOVA) and logistic regressions. An issue with visual analogue scales is that they tend to be skewed and flat and thus do not meet the prerequisites of ANOVA for normally distributed variables. In the present study, these scales were indeed moderately skewed 
Table 1. Means and standard deviations for possible confounding factors by experimental condition

\begin{tabular}{|c|c|c|c|c|c|c|c|c|c|}
\hline & \multirow{2}{*}{$\begin{array}{l}\text { Range } \\
\text { in } \\
\text { sample }\end{array}$} & \multicolumn{2}{|c|}{$\begin{array}{l}\text { Placebo, no water } \\
(\mathrm{n}=17)\end{array}$} & \multicolumn{2}{|c|}{$\begin{array}{l}\text { Placebo, water } \\
(\mathrm{n}=18)\end{array}$} & \multicolumn{2}{|c|}{$\begin{array}{l}\text { Alcohol, no water } \\
(\mathrm{n}=20)\end{array}$} & \multicolumn{2}{|c|}{$\begin{array}{l}\text { Alcohol, water } \\
(\mathrm{n}=19)\end{array}$} \\
\hline & & mean & SD & mean & SD & mean & SD & mean & SD \\
\hline Age & $19-25$ & 21.81 & 1.41 & 21.40 & 1.41 & 22.24 & 1.84 & 21.92 & 1.41 \\
\hline Alcohol use & $1-33$ & 9.15 & 6.30 & 8.64 & 5.07 & 7.95 & 7.87 & 8.47 & 3.36 \\
\hline Binge drinking & $0-5$ & 2.65 & 0.79 & 3.11 & 1.18 & 3.00 & 1.08 & 3.21 & 0.92 \\
\hline \multicolumn{10}{|l|}{ Belief about water } \\
\hline Reduces alcohol & $1-6$ & 3.59 & 1.33 & 3.61 & 1.46 & 3.70 & 1.13 & 3.32 & 1.53 \\
\hline Cleanses body & $2-6$ & 5.24 & 0.56 & 4.94 & 1.06 & 5.15 & 0.49 & 4.79 & 1.18 \\
\hline Sobers up & $1-6$ & 3.35 & 1.46 & 3.78 & 1.44 & 3.40 & 1.14 & 3.26 & 1.49 \\
\hline \multicolumn{10}{|l|}{ Driver's experience } \\
\hline Driver's license & $12-59$ & 32.24 & 15.51 & 33.22 & 15.29 & 35.05 & 15.48 & 36.26 & 12.99 \\
\hline Driving frequency & $1-7$ & 4.47 & 1.13 & 5.00 & 1.19 & 4.50 & 1.40 & 4.63 & 1.30 \\
\hline Drinking and driving & $0-1$ & 0.00 & 0.00 & 0.17 & 0.38 & 0.10 & 0.31 & 0.16 & 0.38 \\
\hline Accident involvement & $0-1$ & 0.47 & 0.51 & 0.50 & 0.51 & 0.20 & 0.41 & 0.58 & 0.51 \\
\hline Health and safety risk taking & $12-31$ & 19.88 & 3.55 & 21.89 & 4.01 & 18.95 & 5.30 & 21.37 & 4.59 \\
\hline Craving for alcohol & $0-59$ & 11.24 & 15.99 & 14.00 & 12.34 & 9.75 & 11.42 & 11.42 & 12.98 \\
\hline Thirst & $1-93$ & 50.24 & 21.74 & 56.22 & 25.53 & 53.05 & 17.20 & 62.00 & 17.06 \\
\hline
\end{tabular}

One-way ANOVAs were used to test the differences between groups; they showed no significant results $(\mathrm{p}>0.05)$.

(range of the scales varied between -0.17 and 1.37 ; kurtosis varied between -1.12 and 1.18). However, ANOVA is quite robust to violations of this assumption if true randomization has occurred and group sizes are about equal [30], which both were true for the present study. To confirm the accuracy of our results, we also performed nonparametric tests. These tests showed identical outcomes.

Overall, participants in the placebo conditions believed they consumed alcohol as they all reported that their cocktail contained one or more glasses of alcohol. After $30 \mathrm{~min}, 68.6 \%$ of all participants reported feeling at least slightly intoxicated (10 points or more on a 100 -point visual analogue scale), even though they did not consume alcohol. The remaining $31.4 \%$ reported almost no feelings of intoxication (score $<10$ ).

As shown in table 1, randomization was successful; no differences between the four conditions were found on possible confounders such as alcohol use or water beliefs. Overall, participants endorsed the purifying properties of water: $63.5 \%$ believed that drinking water reduced the effect of alcohol, $54.1 \%$ believed that water made you sober up faster, and $93.2 \%$ believed that water cleansed the body.

\section{Perceived Level of Intoxication}

An ANOVA showed a main effect of alcohol on perceived intoxication level $\left[\mathrm{F}(1,70)=39.14, \mathrm{p}<0.01, \eta^{2}=\right.$ 0.37]. Women in the alcohol conditions perceived them- selves as more intoxicated $($ mean $=55.68, \mathrm{SD}=20.01)$ than women in the placebo conditions (mean $=26.07$, $S D=20.04)$. Neither a main effect of water, nor an interaction effect between alcohol and water on the perceived intoxication levels was found.

\section{Driving-Related Cognitions}

We tested effects of the combined use of alcohol and water on driving cognitions, i.e. willingness to drive and ability to drive. An ANOVA revealed an effect of alcohol on the perceived ability to drive before entering the driving simulator $\left[\mathrm{F}(1,70)=11.43, \mathrm{p}<0.01, \eta^{2}=0.14\right]$. Women in the alcohol conditions perceived themselves as being less able to drive a car safely (mean $=39.23, \mathrm{SD}=23.38$ ) than women in the placebo conditions (mean $=59.31$, $\mathrm{SD}=26.87$ ). The same effect was found after women had driven in the driving simulator $[\mathrm{F}(1,70)=9.44, \mathrm{p}<0.01$, $\left.\eta^{2}=0.12\right]$. Neither a main effect of water, nor a two-way interaction between water and alcohol on the perceived ability to drive was found before or after driving.

In addition, an ANOVA showed an effect of alcohol on the willingness to drive before driving $[\mathrm{F}(1,70)=11.68$, $\left.\mathrm{p}<0.01, \eta^{2}=0.14\right]$. Women in the alcohol conditions were less willing to drive a car (mean $=16.26, \mathrm{SD}=23.93) \mathrm{com}$ pared with women in the placebo conditions (mean = $39.80, \mathrm{SD}=34.98)$. The same effect was found after driving $\left[\mathrm{F}(1,70)=8.28, \mathrm{p}=0.01, \eta^{2}=0.11\right]$. A trend towards 


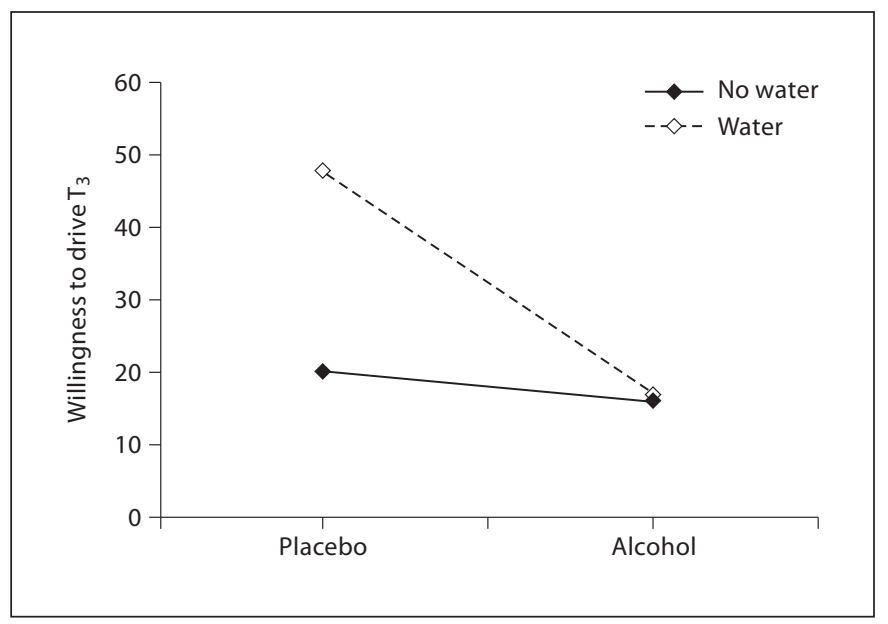

Fig. 1. Effect of water intake on the willingness to drive after performing a simulated driving task moderated by alcohol use.

an effect of water was found before driving $[\mathrm{F}(1,70)=2.87$, $\left.\mathrm{p}=0.10, \eta^{2}=0.04\right)$, which became significant after participants drove $\left[\mathrm{F}(1,70)=5.39, \mathrm{p}=0.02, \eta^{2}=0.07\right]$. Women who drank water showed more willingness to drive (mean $=31.86, \mathrm{SD}=33.41)$ than women who did not drink water (mean $=17.97, \mathrm{SD}=21.53)$. Our findings further showed a two-way interaction between alcohol and water on the willingness to drive after driving $[\mathrm{F}(1,70)=$ $\left.4.80, p=0.03, \eta^{2}=0.06\right]$. Women in the placebo condition who drank water were more willing to drive (mean = $47.72, \mathrm{SD}=6.17$ ) than women in the same condition who did not drink water (mean $=20.24, S D=6.35)$ (fig. 1 ). When participants received alcohol, drinking water did not affect their willingness to drive.

Two three-way interactions between alcohol, water and previous accident involvement were found. An ANOVA including accident involvement showed a trend towards an interaction between alcohol, water and accident involvement on the perceived ability to drive before driving $\left[\mathrm{F}(1,66)=3.63, \mathrm{p}=0.06, \eta^{2}=0.05\right]$. This trend became significant after participants drove the simulator $\left[F(1,66)=5.49, p=0.02, \eta^{2}=0.08\right]$. The effect of water was only shown in women in the placebo condition who had previously been involved in an accident. Women in the placebo condition who drank water perceived themselves as more able to drive safely $($ mean $=68.67, \mathrm{SD}=8.31)$ compared with women in the placebo condition who did not drink water (mean $=43.88, \mathrm{SD}=8.81$ ) (fig. 2). No effects were demonstrated for women in the alcohol conditions.

Another interaction between alcohol, water and accident involvement on the willingness to drive was found

Effects of Water on Driving Cognitions and Behavior

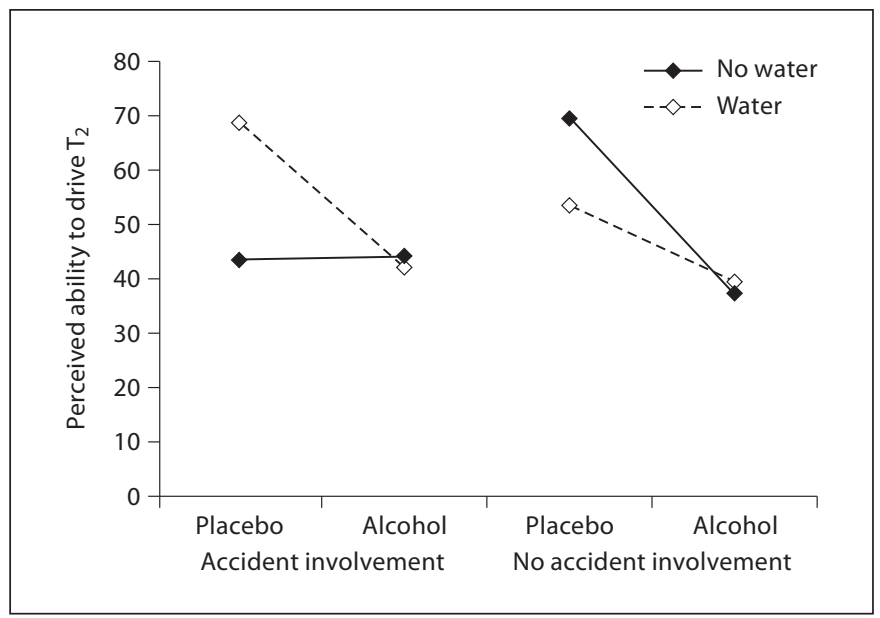

Fig. 2. Perceived ability to drive as a function of water intake, alcohol use and previous accident involvement.

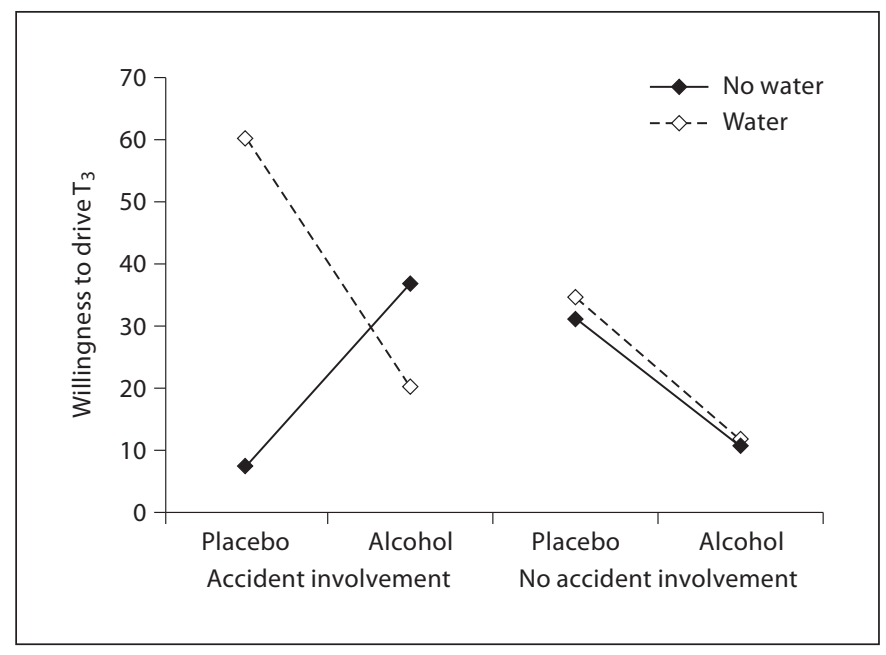

Fig. 3. Willingness to drive after performing a simulated driving task as a function of water intake, alcohol use and previous accident involvement.

after driving $\left[F(1,66)=7.47, p=0.01, \eta^{2}=0.10\right]$. The effect of water was only present in women in the placebo condition who had previously been involved in an accident. These women were more willing to drive (fig. 3). No effects were demonstrated for women in the alcohol conditions or women without a history of accident involvement.

Vehicle Handling and Driving Performance

Vehicle handling was assessed using two measures, i.e. lateral position and speed. We included average speed as 
a covariate since average speed can affect lateral position and its relationship with other variables. Neither main effects of alcohol and water, average speed, nor a two-way interaction between alcohol and water on participants' average lateral position, standard deviation of lateral position (swerving), or average speed were found.

Driving performance was measured using three scenarios. An ANOVA revealed an effect of alcohol on gap acceptance shown in the first scenario $[\mathrm{F}(1,70)=4.53$, $\mathrm{p}=0.04, \eta^{2}=0.06$ ). Women in the alcohol conditions showed smaller accepted gaps $($ mean $=8.20, \mathrm{SD}=1.24)$ than women in the placebo conditions (mean $=8.80$, $\mathrm{SD}=1.27$ ). Neither a main effect of water, nor a two-way interaction between alcohol and water on accepted gap size was found. Furthermore, an ANOVA showed a main effect of alcohol on the distance between the participant's car to the front of the upcoming car $[\mathrm{F}(1,70)=7.80, \mathrm{p}=$ $\left.0.01, \eta^{2}=0.10\right]$. Women in the alcohol conditions showed a smaller distance $($ mean $=27.99, \mathrm{SD}=2.82)$ compared with women in the placebo conditions (mean $=39.44$, $\mathrm{SD}=2.98$ ). The second scenario concerned a traffic light turning orange. A logistic regression analysis was performed, but showed no main or interaction effects of alcohol and water. In the third scenario, the participant's response on suddenly appearing fog was measured. An ANOVA revealed a main effect of water on the minimum speed participants drove $\left[F(1,70)=5.94, p=0.02, \eta^{2}=\right.$ 0.08 ]. Women who drank water drove faster (mean $=$ $50.42, \mathrm{SD}=17.58)$ than women who did not drink water $($ mean $=40.43, \mathrm{SD}=17.77)$. Neither a main effect of alcohol was found, nor a two-way interaction between alcohol and water.

\section{Discussion}

This study examined the effect of the combined use of alcohol and water on driving-related cognitions and behavior during a simulated driving task. We hypothesized that combining alcohol and water could lead to the underestimation of women's perceived intoxication level and would therefore lead to more favorable driving cognitions, resulting in increased risk behavior. Our data did not confirm this hypothesis; drinking water did not affect perceived intoxication level, driving cognitions or driving behavior in women who had consumed alcohol. Surprisingly, water consumption did affect participants' driving speed irrespective of whether they had received alcohol or a placebo. Moreover, in the placebo conditions, water consumption increased women's perceived ability and willingness to drive, but only for those with a history of accident involvement.

Overall, our findings indicate that the combined use of water and alcohol does not influence women's risk cognitions and behaviors. Women who drank alcohol and water did not show lower perceived intoxication levels or increased willingness or ability to drive a car than women who only drank alcohol. Moreover, when actually driving a car, they did not perform worse than intoxicated women who did not drink water. Hence, expectations about the antagonistic effect of water did not have the same detrimental effect as caffeine in the study by Fillmore et al. [8]. This is good news, especially for current outreach prevention projects involving the provision of water. In these projects, water consumption is promoted to people in bars since drinking water increases satiety and thereby decreases alcohol consumption. In the absence of clear counterproductive effects, the combined use of water and alcohol might be a promising strategy to limit one's alcohol use.

Furthermore, results showed that women who had consumed alcohol demonstrated realistic cognitions about their own functioning irrespective of whether they had combined their alcohol use with water or not. Women in the alcohol conditions perceived themselves as more intoxicated, less able to drive a car safely and were less willing to drive a car compared with women in the placebo conditions. As demonstrated in earlier research and in line with their expectations, their driving performance was indeed worse compared with the driving behavior of women in the placebo conditions. Thus, women were well aware of the impact of alcohol and therefore reported to be unwilling and unable to drive a car. The fact that young adult women make accurate estimations about the impact of alcohol on their driving behavior and consequently are less willing to drive is important for policy makers and prevention workers. Of course, this finding may not account for all women since this study sample consisted only of highly educated females.

Interestingly, drinking water affected the minimum speed driven after a sudden incident by participants irrespective of whether they had received alcohol or placebo. This finding seems to indicate that water is in some way able to affect people's cognitions and behavior. An influence might have been exerted through the beliefs people have about water; the majority of women in this study endorsed the purifying properties of water. However, one third of the participants reported not to believe that drinking water reduces the effect of alcohol, and nearly half of all participants did not believe that water 
makes people sober up faster. Although water beliefs were controlled for in the analyses and no differences were found between groups, this matter still needs to be clarified in further research.

Surprisingly, results also showed that driving cognitions and behavior of women in the placebo conditions with a history of accident involvement were affected by water intake. Women in the placebo conditions with a history of accident involvement who drank water demonstrated a firmer belief in their ability to drive a car safely after supposed alcohol intake compared with those who did not drink water. This belief was also represented in the findings concerning the reported willingness to drive. Women in the placebo conditions who drank water and had been involved in an accident were more willing to drive compared with women who drank water but had not been involved in an accident. Thus, drinking water seems to increase the willingness to engage in risky behavior in women with a history of accident involvement. Unfortunately, it is unclear how this unexpected association between accident involvement and water intake in the placebo condition should be interpreted since it is well possible that the interactions we found between water consumption and accident involvement were caused by a residual confounder.

For future research, several suggestions can be made. First, the effects of drinking water on men's cognitions and behavior should be examined. Although women who drank alcohol were not affected by water intake, water may have a different impact on males; men show higher levels of risk taking and alcohol use than women [26, 3133], which may alter the effect of water on their cognitions and behavior. Future research should also gain insight into the variable causing the apparent association between water consumption and accident involvement. Furthermore, future studies should more closely examine people's beliefs concerning water; why are these beliefs endorsed by some people and not by others and whether these beliefs have an impact on other (risk) behaviors? Future research could also focus on testing the effect of water in a naturalistic setting (e.g. providing water in bars) to assess to what extent these experimental results translate into real life. Lastly, the effect of water in other samples than college students could be addressed by future studies.

One important limitation of this study is that consumption was not dosed by participants themselves in a natural drinking setting. Therefore, no statements can be made regarding the ecological validity of our findings. Moreover, the fact that one third of all participants in the placebo conditions reported to feel almost no symptoms of intoxication may have influenced our results. Thirdly, sample sizes in three-way interactions were somewhat narrow and might reflect outlier effects. Although exploration of the data showed no such indications, studies incorporating larger samples should further examine this matter. Finally, the bogus purpose of the study (i.e. the effects of alcohol on driving performance) might have influenced participants' responses.

In spite of these limitations, this study points out that young adult females who drank alcohol have realistic and accurate cognitions about their own functioning related to driving. Beliefs about water do not seem to influence their cognitions or behavior. Apparently lacking a counterproductive effect, providing water could be a promising way of limiting alcohol intake among young adults.

\section{Acknowledgements}

We would like to thank Janet Veldstra for her support in setting up the driving task. We also thank Peter van Wolffelaar and Linus Wiggers for their assistance. Lastly, we are grateful to the Department of Experimental \& Work Psychology at the University of Groningen for putting their driving simulator at our disposal for pretesting.
References

Effects of Water on Driving Cognitions and Behavior

\footnotetext{
1 Hall AP, Henry JA: Acute toxic effects of 'Ecstasy' (MDMA) and related compounds: overview of pathophysiology and clinical management. Br J Anaesth 2006;96:678685.

2 Negoianu D, Goldfarb S: Just add water. J Am Soc Nephrol 2008; 19:1-3.

3 Valtin H: 'Drink at least eight glasses of water a day.' Really? Is there scientific evidence for ' 8 × 8'? Am J Physiol Regul Integr Comp Physiol 2002;283:993-1004.
}

-4 Dixon RS, Gill JM, Adair VA: Exploring paternal influences on the dieting behaviors of adolescent girls. Eat Disord 2003;11:39-50.

5 Ferrier C: Bottled water: understanding a social phenomenon. Ambio 2001;30:118-119.

6 Wilk R: Bottled water: the pure commodity in the age of branding. J Consum Cult 2006; 6:303-325.

7 Harrison ELR, Fillmore MT: Social drinkers underestimate the additive impairing effects of alcohol and visual degradation on behavioural functioning. Psychopharmacology $2005 ; 177: 459-464$.

and Behavior 
8 Fillmore MT, Roach EL, Rice JT: Does caffeine counteract alcohol-induced impairment? The ironic effects of expectancy. J Stud Alcohol 2002;63:745-754.

-9 Ogurzsoff S, Vogel-Sprott M: Low blood alcohol discrimination and self-titration skills of social drinkers with widely varied drinking habits. Can J Behav Sci 1976;8:232-242.

$>10$ Beirness DJ: Self-estimates of blood alcohol concentration in drinking-driving context. Drug Alcohol Depend 1987;19:79-90.

11 NHTSA: Traffic Safety Facts 1998:Alcohol. DOT HS 808 950. National Highway Traffic Safety Administration, 1999.

$>12$ Liguori A, Gatto CP, Jarrett DB: Separate and combined effects of marijuana and alcohol on mood, equilibrium and simulated driving. Psychopharmacology 2002;163: 399-405.

-13 Weiler JM, Bloomfield JR, Woodworth GG, Grant AR, Layton TA, Brown TL, et al: Effects of fexofenadine, diphenhydramine, and alcohol on driving performance. A randomized, placebo-controlled trial in the Iowa Driving Simulator. Ann Intern Med 2000; 132:354-363.

14 Burian SE, Liguori A, Robinson JH: Effects of alcohol on risk-taking during simulated driving. Hum Psychopharmacol 2002;17: 141-150.

15 Hurst PM, Harte D, Frith WJ: The Grand Rapids dip revisited. Accid Anal Prev 1994; 26:647-654.

16 Krüger HP, Kazenwadel J, Vollrath M: Grand Rapids effects revisited; accidents, alcohol and risk. Alcohol, drugs and traffic safety. Proc 13th Int Conf on Alcohol, Drugs and Traffic Safety, 1995, vol 1, pp 222-230.
17 Triggs TJ, Smith KB: Young driver research program: Digest of reports and principal findings of the research, report No. CR 164. Federal Office of Road Safety, 1996.

18 Elliot MR, Waller PF, Raghunathan TE, Shope JT, Little RJA: Persistence of violation and crash behavior over time. J Safety Res 2000;31:229-242.

19 Deery HA, Fildes BN: Young novice driver subtypes: relationship to high-risk behavior, traffic accident record, and simulator driving performance. Hum Factors 1999;41:628643.

20 Devriese S, Huybrechts I, Moreau M, Van Oyen H: De Belgische Voedselconsumptiepeiling 1 - 2004 (Report No. 2006-016). Retrieved from Scientific Institute of Public Health: http://www.iph.fgov.be/epidemio/ epinl/foodnl/table04.htm.

21 Deitrich RA, Palmer JD: Alcohol; in Brody TM, Larner J, Minneman KP (eds): Human Pharmacology: Molecular to Clinical. St Louis, Mosby, 1998, pp 435-445.

22 Mourant RR, Thattacherry TR: Simulator sickness in a virtual environments driving simulator. Proceedings of the IEA 2000/ HFES 2000 Congress.

23 Dotinga A, Van den Eijnden RJ, Bosveld W Garretsen HFL: The effect of data collection mode and ethnicity of interviewer on response rates and self-reported alcohol use among Turks and Moroccans in the Netherlands: an experimental study. Alcohol Alcohol 2005;40:242-248.

24 Brookhuis KA, De Waard D, Samyn N: Effects of MDMA (ecstasy), and multiple drugs use on (simulated) driving performance and traffic safety. Psychopharmacology 2004; 173:440-445.
25 De Waard D, Kruizinga A, Brookhuis KA: The consequences of an increase in heavy goods vehicles for passenger car drivers' mental workload and behaviour: a simulator study. Accid Anal Prev 2008;40:818-828.

26 Yan X, Radwan E, Guo D: Effects of majorroad vehicle speed and driver age and gender on left-turn gap acceptance. Accid Anal Prev 2007;39:843-852.

27 De Waard D, Van der Hulst M, Brookhuis KA: Elderly and young drivers' reaction to an in-car enforcement and tutoring system. Appl Ergon 1999;30:147-157.

28 Fillmore MT, Blackburn JS, Harrison ELR: Acute disinhibiting effects of alcohol as a factor in risky driving behavior. Drug Alcohol Depend 2008;95:97-106.

29 Blais AR, Weber EU: A Domain-Specific Risk-Taking (DOSPERT) scale for adult populations. Judgm Decis Mak 2006;1:33-47.

30 DeCarlo LT: On the meaning and use of kurtosis. Psychol Methods 1997;2:292-307.

31 Ahlers MJ: Gezondheidsgedrag eerstejaars studenten: onderzoek naar het gezondheidsen seksuele gedrag bij eerstejaars studenten van de Rijksuniversiteit Groningen. Retreived from Universitair Medisch Centrum Groningen:http://umcg.wewi.eldoc.ub.rug. nl/FILES/root/Rapporten/2005/Gezondheidsgedrag/Gezondheidsgedragrapport. pdf.

32 Byrnes JP, Miller DC, Schafer WD: Gender differences in risk-taking: a meta-analysis. Psychol Bull 1999;125:367-383.

33 Lajunen T, Summala H: Driving experience, personality, and skill and safety-motive dimensions in drivers' self-assessments. Pers Individ Dif 1995;19:307-318. 